15 Peters BS, Bennett JM, Jeffries DJ, Knox K, Kocsis A, Pinching AJ Ineffectiveness of AL721 in HIV disease. Lancet 1990;335:545-6.

16 Rothenberg R, Woelfel $M$, Stoneburner R, Milberg J, Parker R, Truman B. Survival with the acquired immunodeficiency syndrome. $N$ Engl $f$ Med 1987;317:1297-302.

17 Gardner TD, Hanson PVJ, Griffiths PD, Collins JV, Gazzard BG. Diagnosis, treatment and outcome of pneumonia in the acquired immune deficiency syndrome. $\mathcal{F}$ Infect 1989;18:111-7.

18 Brenner M, Ognibene FP, Lack EE, et al. Prognostic factors and life expectancy of patients with acquired immunodeficiency syndrome and
Pneumocystis carinii pneumonia. Am Rev Respir Dis 1987;136:1199-206. 19 Penn I. The occurrence of malignant tumours in immunosuppressed states. Prog Allergy 1986;37:259-300

20 Peters BS, Matthews J, Gompels M, Hartley JC, Pinching AJ. Acut myeloblastic leukaemia in AIDS. AIDS 1990;4:367-8.

21 Swart AM, Weller I, Darbyshire JH. Early HIV infection: to treat or not to treat? BMF 1990;301:825-6.

\title{
Use of non-orthodox and conventional health care in Great Britain
}

\author{
Kate J Thomas, Jane Carr, Linda Westlake, Brian T Williams
}

\begin{abstract}
Objective-To describe the characteristics of patients using non-orthodox health care and their pattern of use of conventional health care with respect to a particular problem.
\end{abstract}

Design-Postal survey of all 2152 practitioners of acupuncture, chiropractic, homoeopathy, naturopathy, and osteopathy identified from 11 national professional association registers. Patients attending a representative sample of 101 responding practitioners completed questionnaires covering demographic characteristics, presenting problems, and use of the health service.

Setting-Practices of practitioners of nonorthodox health care in England, Scotland, and Wales.

Subjects-Qualified, non-medical practitioners of non-orthodox health care working in Great Britain and 2473 patients who had attended one of the sampled practitioners in an allocated time period between August 1987 and July 1988.

Results-An estimated 1909 practitioners were actively practising one of the study treatments in Great Britain in 1987. Of the estimated 70600 patients seen by this group of practitioners in an average week, most $(78 \%)$ were attending with a musculoskeletal problem. Two thirds of the patients were women. Only $2 \%$ were aged under 16 , but $15 \%$ were aged 65 or over. One in three patients had not received previous conventional care for their main problem; $18 \%$ were receiving concurrent nonorthodox and conventional care. Twenty two per cent of the patients reported having seen their general practitioner for any reason in the two weeks before the surveyed consultation.

Conclusions-Patients of non-orthodox health care, as provided by this group of practitioners, had not turned their backs on conventional health care. Non-orthodox treatment was sought for a limited range of problems and used most frequently as a supplement to orthodox medicine.

Medical Care Research

Unit, Department of Public Health Medicine,

University of Sheffield

Medical School, Sheffield

S10 2RX

Kate J Thomas, MA, senior

research associate

Jane Carr, BSC, research

assistant

Linda Westlake, BSC, statistician

Brian T Williams, FRCP, director

Correspondence to: Ms Thomas.

BMF 1991;302:207-10 ture, chiropractic, homoeopathy, and osteopathy considerable. Such training is being pursued both by medically qualified practitioners and by those without previous medical training.

In the United Kingdom, unlike in most other
European countries, a practitioner without a registered medical qualification may legally offer health care for payment and, at present, there is no formal regulation of practice. This state of affairs may change because of pressures from home and abroad for greater regulation and control. General Medical Council guidelines make possible referrals to practitioners who do not possess medical qualifications, provided that the referring medical practitioners retain responsibility for their patients. ${ }^{5}$ The extent of this responsibility requires clarification and is perceived as a problem by some general practitioners. ${ }^{6}$ At the same time some qualified, non-medical practitioners of the more established treatments are actively seeking statutory registration for their disciplines.

No statutory statistical information exists to inform the debates surrounding these issues. Our study goes some way to providing such data by describing the characteristics and behaviour of a national sample of non-orthodox health care practitioners and their patients and the way in which such patients make use of the two systems of health care over time and with respect to particular problems.

\section{Methods}

We focused on a particular type of non-orthodox care - that provided by qualified, non-medical practitioners belonging to national professional associations that regulate the practice of their members. All the practitioners in the study were trained in acupuncture, chiropractic, homoeopathy, medical herbalism, naturopathy, or osteopathy. The study entailed an initial postal survey, conducted in March 1987, of 2152 practitioners identified from the registers of 11 national professional associations representing practitioners in the six disciplines.

The second stage entailed a survey of the patients of a stratified random sample of 146 active practitioners, identified from the postal survey. The practitioners were stratified before sampling according to professional association membership and the length of time each practitioner had been in practice. A sample size of $5 \%$ was chosen for the six associations with membership over $100,10 \%$ for the four with membership under 100 , and $20 \%$ for the smallest association. All patients attending each of these practitioners were sampled during a specified time period allocated to each practitioner between August 1987 and July 1988. The duration of the sample period ranged from three days to two weeks, depending on the level of activity of each practitioner; a minimum of 25 patients per practitioner was sampled. The sample sizes were selected to ensure that sufficient numbers of patients were sampled within each of the diagnostic categories, thus producing a representative range of the problems presented to these non-orthodox health care practitioners. For each patient attending in the sample 
period a short questionnaire was completed by the practitioner, and a further, more detailed, questionnaire was given to the patient by the practitioner, to be returned directly to the research team. Patients attending more than once in the sample period were surveyed only on their first attendance.

To account for the varying duration of the sample period of each practitioner, normal working patterns, patient response rates, and the stratification of the associations' data on patients were weighted to obtain estimates of the standard average weekly numbers and characteristics of patients seen by the total practitioner population. Confidence intervals to account for any sampling error were calculated for these average weekly estimates by using the actual sample numbers for each practitioner and then reweighting. The data on patients' descriptions of their main and subsidiary problems at the sampled consultation were coded according to the World Health Organisation's International Classification of Primary Health Care by using the "reason for encounter" mode." Data from the population based general household survey of 1983 were analysed to provide demographic comparisons of patients attending NHS general practitioners. ${ }^{8}$

\section{Results}

Of the 2152 questionnaires sent to practitioners identified in the first stage of the study, 1575 replies were received $(73 \%)$. From these replies it was established that 26 practitioners were medically qualified; 18 could not be traced at the address given in the association register and 132 had either stopped practising or were no longer in practice in Britain. The response rate for eligible practitioners, excluding these three categories, ranged from $60 \%$ to $86 \%$ (median $72 \%$ ) for the 11 associations. Taking into account practitioners written to twice as members of more than one association and the variation in response rates for each association, we estimated that 1909 non-medically qualified practitioners were actively practising one of the six disciplines as a member of one of the main professional associations in Great Britain in 1987. Practitioners' own estimates of their normal workload suggested that this group of non-orthodox practitioners undertook four million consultations in 1987, roughly one for every 55 patient consultations with a general practitioner in the NHS.

Among the treatments endorsed by a professional association membership, chiropractic and osteopathy were offered by the majority of practitioners (1107 $(58 \%))$, including naturopaths, who undergo a dual training. Ninety six $(5 \%)$ of the practitioners claimed to be registered with more than one of the professional associations covered by the study, and these claims were verified in updated association registers. A further 238 practitioners $(12 \%)$ offered a treatment included in the study without being a member of one of the associations. Chiropractors and osteopaths who did not also offer naturopathy were much less likely than other groups of practitioners to offer more than one type of treatment (table I).

When the eight sampled medical herbalists, who withdrew as a group from the study after the first stage, were excluded the second stage patient survey recruited $73 \%$ of the practitioners approached (101/ 138); 11 practitioners refused, 18 had either moved or stopped practising between the two stages of the study, and eight failed to complete the data collection. The achieved sample of practitioners was representative of the estimated population with respect to main treatment offered, age, sex, hours worked, and consultations reported a week. The achieved sample comprised 24 acupuncturists, 21 chiropractors, seven homoeopaths, six naturopath-osteopaths, 36 osteopaths, and seven practitioners who offered more than one of the study treatments and belonged to more than one of the professional assocations.

Information was provided on 3082 patients by these 101 practitioners, and $80 \%$ (2473) of these patients returned matched questionnaires. When the practitioner completed questionnaires were compared with the patient completed questionnaires little difference was found between the responders and non-responders with respect to age or sex; in addition, there was no evidence to suggest that the professional association membership of the practitioner had any effect on the response rates of patients. Weighting the data for the 2473 patients for whom a patient completed questionnaire was available produced an estimate of 70600 (95\% confidence interval 67800 to 73400 ) individual patients who consulted this group of practitioners (excluding medical herbalists) on average each week in 1987-8. This estimated average week is the unit used to describe patient characteristics and case mix in all subsequent tables.

As in general practice in the NHS, proportionally more adult patients were female. The age distribution of adult patients differed, however, from that seen in general practice; in particular, only $15 \%(10400)$ were aged over 65 (table II). Only $2 \%$ of all patients (1300) were aged under 16 years.

New patients (those who had not visited one of the surveyed non-orthodox practitioners before) made up an estimated $10 \%(7000)$ of the patients seen in an average week, representing an estimated $360000(95 \%$ confidence interval 356000 to 374000 ) people over 12 months. Two thirds of these patients claimed never to have used any non-orthodox health care previously.

The majority of patients $(64 \%(43200))$ reported having received orthodox treatment for their main problem from their general practitioner or a hospital

TABLE I-Main treatment offered and use of multiple treatments by membership of professional association for estimated numbers (percentages) of registered non-orthodox practitioners in 1987

\begin{tabular}{lcc}
\hline & Registered & $\begin{array}{c}\text { Practitioners in each } \\
\text { group offering multiple } \\
\text { treatments and having } \\
\text { membership of only on } \\
\text { association }\end{array}$ \\
\hline Main treatment & $507(27)$ & $100(20)$ \\
Acupuncture & $290(15)$ & $6(2)$ \\
Homiropractic & $93(5)$ & $12(13)$ \\
Medicapathy & $115(6)$ & $45(39)$ \\
Naturopathy with osteopathy & $128(7)$ & $41(32) \dagger$ \\
Osteopathy & $680(36)$ & $34(5)$ \\
Member of $>1$ association & $96(5)$ & -- \\
\hline Total & $1909(100)$ & $238(12)$ \\
\hline
\end{tabular}

* Sample size $=1575$.
†Practitioners offering at least one treatment in addition to naturopathy and osteopathy.

TABLE II - Sex and age of patients consulting non-orthodox health care practitioners in an average week and NHS general practitioners over two weeks

\begin{tabular}{|c|c|c|c|}
\hline & \multicolumn{2}{|c|}{$\begin{array}{l}\text { Consulting non-orthodox health } \\
\text { care practitioners }\end{array}$} & \multirow[b]{2}{*}{$\begin{array}{c}\% \text { Consulting } \\
\text { NHS general practitioners }\end{array}$} \\
\hline & $\begin{array}{l}\text { Estimated No } \\
(\text { Total }=68400)\end{array}$ & $\%$ & \\
\hline \multicolumn{4}{|c|}{ Sex } \\
\hline Men & $25000+$ & 37 & 38 \\
\hline \multicolumn{3}{|c|}{ Age (years) } & 62 \\
\hline $16-24$ & $3100 \ddagger$ & 4 & 16 \\
\hline $25-34$ & $11200^{\top}$ & 16 & 17 \\
\hline $35-44$ & 17100 & 2 & 14 \\
\hline $45-54$ & 13800 & 20 & 13 \\
\hline $55-64$ & 12800 & 19 & 15 \\
\hline $65-74$ & 7400 & 11 & 15 \\
\hline$\geqslant 75$ & 3000 & 4 & 11 \\
\hline
\end{tabular}

*General household survey data, $1983(\mathrm{n}=2978)$

†Sex not known for 400

$\ddagger$ Age not known for $500 ; 1300<16$ years. 
TABLE III - Source of previous treatment for main problem (estimated numbers (percentages)) and proportion of each group receiving concurrent orthodox treatment from general practitioner $(G P)$ or hospital specialis

\begin{tabular}{lcrr}
\hline & & $\begin{array}{c}\text { Proportion receiving } \\
\text { concurrent orthodox } \\
\text { treatment }\end{array}$ \\
\cline { 3 - 4 } Source of previous treatment & Estimated No $(\%)$ & Estimated No & $\%$ \\
\hline GP only & $12500(18)$ & 3200 & 25 \\
GP and hospital specialist & $10100(15)$ & 2800 & 27 \\
Hospital specialist only & $11900(18)$ & 2000 & 16 \\
Orthodox with non-orthodox practitioners & $8700(13)$ & 2400 & 27 \\
\hline Total & $43200(64)$ & 10400 & 24 \\
\hline Non-orthodox health care practitioner only & $6300(9)$ & 600 & 9 \\
No previous treatment & $18300(27)$ & 1400 & 8 \\
\hline Total & $24600(36)$ & 2000 & 8 \\
\hline Total & $67800(100)$ & 12400 & 18 \\
\hline
\end{tabular}

$\star$ Not known for estimated 2800 .

TABLE IV-Distribution of problems reported by patients consulting practitioners of non-orthodox health care in average week

\begin{tabular}{|c|c|c|c|c|}
\hline \multirow[b]{2}{*}{ Reason for encounter ${ }^{\star}$} & \multicolumn{2}{|c|}{ Main problem $\dagger$} & \multicolumn{2}{|c|}{ All problems } \\
\hline & $\%($ Total $=69200)$ & $\begin{array}{c}\text { Sample size } \\
(\text { Total }=2424)\end{array}$ & $\%($ Total $=111800)$ & $\begin{array}{c}\text { Sample size } \\
(\text { Total }=4054)\end{array}$ \\
\hline General (including check up) & $3 \cdot 7$ & 95 & $4 \cdot 0$ & 183 \\
\hline Blood & $0 \cdot 1$ & 4 & $0 \cdot 1$ & 4 \\
\hline Digestive & $1 \cdot 6$ & 44 & $2 \cdot 0$ & 109 \\
\hline Eye & $0 \cdot 1$ & 4 & $0 \cdot 3$ & 16 \\
\hline Ear & $0 \cdot 3$ & 13 & $0 \cdot 3$ & 18 \\
\hline Circulatory & 0.5 & 12 & 1.0 & 37 \\
\hline Musculoskeletal & $78 \cdot 2$ & 1809 & $73 \cdot 7$ & 2817 \\
\hline Neurological & $5 \cdot 6$ & 145 & $7 \cdot 3$ & 301 \\
\hline Psychological & $4 \cdot 6$ & 109 & $5 \cdot 3$ & 233 \\
\hline Respiratory & 1.9 & 70 & $1 \cdot 8$ & 124 \\
\hline Skin & 0.9 & 39 & $1 \cdot 0$ & 64 \\
\hline Metabolic & 0.9 & 17 & $1 \cdot 0$ & 30 \\
\hline Urinary & $0 \cdot 6$ & 14 & $0 \cdot 7$ & 30 \\
\hline Pregnancy & $0 \cdot 2$ & 9 & $0 \cdot 2$ & 13 \\
\hline \multicolumn{5}{|l|}{ Genital: } \\
\hline Female (including breasts) & $0 \cdot 8$ & 33 & $1 \cdot 1$ & 62 \\
\hline Male & $0 \cdot 1$ & 5 & $0 \cdot 1$ & 7 \\
\hline Social & $0 \cdot 1$ & 2 & $0 \cdot 1$ & 6 \\
\hline
\end{tabular}

*International Classification of Primary Care.

tNot known for estimated 1400 , sample size 49.

TABLE $\mathrm{V}-$ Distribution of patient defined problems according to previous and concurrent orthodox treatment for patients consulting non-orthodox health care practitioners in average week

\begin{tabular}{lccccc}
\hline \multicolumn{5}{c}{ Treatment group \% } \\
\cline { 2 - 5 } & $\begin{array}{c}\text { No previous } \\
\text { or concurrent } \\
\text { orthodox care }\end{array}$ & $\begin{array}{c}\text { Previous } \\
\text { orthodox } \\
\text { care only }\end{array}$ & $\begin{array}{c}\text { Previous } \\
\text { and concurrent } \\
\text { orthodox care }\end{array}$ & Estimated No & Sample size \\
\hline Patient defined problem & 47 & 46 & 7 & 6900 & 229 \\
Neck & 35 & 50 & 15 & 11600 & 397 \\
Back & 38 & 55 & 6 & 9600 & 305 \\
Low back & 31 & 42 & 27 & 3500 & 100 \\
Arthritis & 32 & 61 & 7 & 1300 & 49 \\
Fatigue/unwell & 18 & 61 & 21 & 2400 & 85 \\
Headache/migraine & 39 & 44 & 17 & 2600 & 81 \\
Anxiety/stress/depression & 3 & 44 & 53 & 1100 & 52 \\
Atopic conditions & 4 & 86 & 10 & 1000 & 36 \\
Digestive system disorders & 33 & 49 & 17 & 25200 & 949 \\
Other & 34 & 50 & 15 & $65300 \dagger$ & 2283 \\
\hline All patients & 34 & & & \\
\hline
\end{tabular}

^Includes patients with previous orthodox treatment combined with previous non-orthodox treatment. †Treatment state or main problem not known or not applicable in estimated 5300, sample size 190.

specialist before receiving their present non-orthodox treatment, of whom $24 \%$ (10 400) reported also being in receipt of concurrent conventional care (table III) The remaining $36 \%$ (24600) reported that they had not received any conventional treatment from their genera practitioner or a hospital specialist before receiving their non-orthodox care. This does not preclude the possibility that they sought the advice of their general practitioner before seeking non-orthodox care, although, as a group, these patients seemed to have less contact with their general practitioners than did other patients. Eighteen per cent of this group (4600) reported having seen their general practitioner, for any reason in the two weeks before the surveyed nonorthodox consultation, compared with $26 \%$ (11800) of the patients who had received previous orthodox treatment and 22\% (15 500) of all patients. Patients who had not received previous conventional treatment were also more likely to report that they were not registered with a local general practitioner $(3 \%(2000))$ compared with patients who had received previous conventional treatment $(1 \%(700))$. A small proportion $(8 \%(2000))$ of those patients with no previous orthodox treatment reported concurrent conventional treatment for their main complaint (table III); some of these patients may have visited their general practitioner as a result of their consultation with the non-orthodox health care practitioner. In this study the practitioners reported making a positive recommendation for this course of action for 3\% (2000) of all patients seen in an average week.

Using the broad chapter categories from the International Classification of Primary Health Care, we found that musculoskeletal problems accounted for the majority $(78 \%(54100))$ of the main problems reported in an average week and nearly three quarters $(74 \%(82400))$ of all problems reported (table IV). To examine the ways in which the behaviour and characteristics of patients might be related to the problems with which they were attending we used the more detailed International Classification of Primary Health Care codes to create nine discrete patient defined problem groups. Under this classification a strong association was observed between the type of problem that patients reported as their main reason for consulting the non-orthodox practitioner and their use of the two systems of health care (table V). In particular, patients reporting atopic conditions, headaches, and arthritis were more likely to report the combination of previous and concurrent conventional treatment; all these patients reported that they were currently receiving medically prescribed drug treatment.

\section{Discussion}

The possibility that patients such as those in our study have rejected orthodox health care was first raised in the British Medical Association report and ascribed to a "flight from science" or a failure to understand the benefits available from modern orthodox medicine. ${ }^{+}$Overall, our findings suggest that the patients seeking non-orthodox health care from this group of practitioners have continued to make use of orthodox medicine; almost a quarter of all patients had visited their general practitioner, for any reason and on their own behalf, in the two weeks preceding the surveyed consultation, and two thirds had received conventional treatment for their main problem, either before their non-orthodox care or concurrent with it. A substantial minority (36\%), however, seems to have sought help directly from a non-orthodox practitioner, and most of this group did not report any contact with their general practitioner in the two weeks preceding the survey.

On the subject of statutory registration, the government clearly thinks that all these professions must show individually their suitability for inclusion among the state regulated professions. One potential disadvantage of this approach would be the anomalous status of practitioners offering more than one type of treatment. This study showed that, even among the most highly self regulated groups of non-orthodox practitioners, the use of multiple therapeutic approaches was quite common. State recognition of one qualification could confer credibility on all the activities of the practitioner, regardless of the training in the supplementary disciplines. ${ }^{9}$

Though the future relation between the two systems of care remains uncertain, ${ }^{10}$ the current relation, in terms of use by patients, is clearly described in our study. Overall, our evidence suggests that, as a 
separate system of private health care, non-orthodox health care as provided by this group of practitioners is not deflecting appreciable demand away from the NHS, partly because of the range of problems treated and the scale on which care is provided but mainly because most patients using non-orthodox care have not turned their backs on conventional care. In this way non-orthodox health care seems to be used more often as a supplement to than as a substitute for conventional care. If, however, legitimate patient needs are being met by this group of practitioners and without evidence of greater detriment than ensues from conventional treatment the system of nonorthodox health care that they provide may best be described as having a complementary role to play in health care in the 1990s.

We thank the practitioners and their patients who participated in this study. The work was funded by the Nuffield Provincial Hospitals Trust, which we thank for its support.
This unit is funded by the Department of Health and Trent Regional Health Authority. The views expressed in this paper are, however, ours alone.

1 Davies P. Report on trends in complementary medicine. London: Institute for Complementary Medicine, 1987.

2 Conters' Association. Magic or medicine? Which? 1986 Oct: 443-7.

3 Fulder SJ, Muntro RE. Complementary medicine in the United Kingdom patients, practitioners and consultations. Lancet 1986; ii: $542-5$.

4 Board of Science and Education. Alternative therapies. London: British Medical Association, 1986.

5 General Medical Council. Professional conduct and discipline: fitness to practice. London: GMC, 1987.

6 Murray J, Shepherd S. Alternative or additional medicine. A new dilemma for the doctor. F R Coll Gen Pract 1988;38:511-4.

7 Lamberts H, Wood M. ICPC, International classification of primary health care. Oxford: Oxford University Press, 1987.

8 Office of Population Censuses and Surveys. General household survey 1983. London: HMSO, 1984

9 Inglis B. Alternative medicine: is there a need for registration? Lance 1985; ; $95-6$

10 House of Lords Official Debate (Hansard) 1990. (Medicine: complementary and conventional treatments.) May 9;9:cols 1400-36.

(Accepted 12 November 1990)
Melbourne Diabetic Nephropathy Study Group

Abstract

Objective-To compare the efficacy of angiotensin converting enzyme inhibition with calcium antagonism in diabetic patients with microalbuminuria.

Design-Randomised study of diabetic patients with microalbuminuria treated with perindopril or nifedipine for 12 months and monitored for one or three months after stopping treatment depending on whether they were hypertensive or normotensive. Patients were randomised separately according to whether they were hypertensive or normotensive.

Setting-Diabetic clinics in three university teaching hospitals.

Patients-50 diabetic patients with persistent microalbuminuria. In all, $\mathbf{4 3}$ completed the study: $\mathbf{3 0}$ were normotensive and 13 hypertensive; 19 had type I diabetes and 24 had type II diabetes.

Interventions-For 12 months 20 patients were given perindopril $2-8 \mathrm{mg}$ daily and 23 were given nifedipine $20-80 \mathrm{mg}$ daily.

Main outcome measures-Albumin excretion rate, blood pressure, and glomerular filtration rate.

Results-Both perindopril and nifedipine significantly reduced mean blood pressure. During treatment there was no significant difference between those treated with perindopril and those treated with nifedipine with respect to albuminuria or mean blood pressure. Stopping treatment with both drugs was associated with a sustained increase in albuminuria and mean blood pressure. There was a significant correlation between mean blood pressure and albuminuria and also between the reduction in mean blood pressure and the decrease in albuminuria during treatment with both drugs. In hypertensive patients both drugs caused significant decreases in mean blood pressure and albuminuria. In normotensive patients there was no significant reduction in albuminuria with either regimen.

Conclusions - In diabetic patients with microalbuminuria blood pressure seems to be an important determinant of urinary albumin excretion. Perindopril and nifedipine have similar effects on urinary albumin excretion, both preventing increases in albuminuria in normotensive patients and decreasing albuminuria in hypertensive patients.

\section{Introduction}

A proportion of patients with diabetes show modest increases in urinary albumin excretion without being positive for proteinuria on dipstick testing. ${ }^{1}$ This condition is known as microalbuminuria and is considered to represent an early stage of diabetic nephropathy because patients with microalbuminuria often subsequently develop established diabetic nephropathy and overt proteinuria. ${ }^{14}$ Preventing or retarding the progression of microalbuminuria to proteinuria may delay or reduce the risk of end stage renal failure due to diabetes.

Over the past decade studies in patients with various forms of renal disease have suggested that antihypertensive treatment may ameliorate glomerular injury..$^{5-7}$ Some of these studies have suggested that angiotensin converting enzyme inhibitors may confer a benefit additional to conventional antihypertensive treatment in retarding the glomerulopathy associated with renal ablation ${ }^{8}$ or streptozocin induced diabetes. ${ }^{9}$ There is also some experimental evidence that dihydropyridine calcium antagonists may improve renal function or reduce proteinuria in several models of glomerular injury. ${ }^{1011}$ In humans clinical trials have indicated that antihypertensive treatment retards the rate of decline in renal function and reduces proteinuria in hypertensive diabetic subjects with established nephropathy. ${ }^{1213}$ Also, albuminuria was shown to decrease during separate studies with conventional antihypertensive agents ${ }^{14}$ and with the angiotensin converting enzyme inhibitor enalapril ${ }^{15}$ in microalbuminuric diabetic subjects. Several studies have been performed over the relatively short period of two to eight weeks that have directly compared angiotensin converting enzyme inhibitors with other antihypertensive agents in either normotensive ${ }^{16}$ or hypertensive ${ }^{17}$ diabetic patients with microalbuminuria.

The primary aim of the present study was to compare the effects of the angiotensin converting enzyme inhibitor perindopril (Servier, Neuilly, France) with 